\title{
Some Factors Affecting the Breakdown Strength of Solid Dielectrics: A Short Review
}

\author{
M. G. Danikas \\ Democritus University of Thrace \\ School of Engineering \\ Department of Electrical \& Computer \\ Engineering \\ Xanthi, Greece
}

\author{
G. E. Vardakis \\ Democritus University of Thrace \\ School of Engineering \\ Department of Electrical \& Computer \\ Engineering \\ Xanthi, Greece
}

\author{
R. Sarathi \\ Indian Institute of Technology \\ Madras \\ Department of Electrical \\ Engineering \\ Chennai, India
}

\begin{abstract}
This paper refers to some factors affecting the breakdown strength of solid insulating materials. Solid insulating materials play a most important role in the high voltage industry. Factors, such as area effect, crystallinity, impregnation with liquids, temperature, the role of interfaces and mechanical stressing, are investigated and commented upon.
\end{abstract}

Keywords-solid dielectrics; solid insulation; breakdown strength; crystallinity; amorphous regions; temperature; interfaces; mechanical stressing

\section{INTRODUCTION}

Solid insulating materials are essential for the good functioning of high voltage equipment in most applications [13]. Such materials include traditional materials, such as paper, as well as polymeric materials and - more recently - polymer nanocomposites. Various factors, such as the shape of electrodes, their area, the applied electric field, gap spacing, the structure and type of polymeric materials, their molecular weight, types of additives, water and gas content, type of voltage waveform used, pressure of the impregnant (if any), have an effect on the breakdown strength of solid dielectrics. In the following sections a short review of some of the aforementioned factors will be given.

\section{AREA EFFECT OF THE ELECTRODES}

The influence of the area of the electrodes affecting the breakdown strength of high voltage insulation in general is well known, especially from the research with insulating liquids [4, 5]. Such a phenomenon exists also when investigating the breakdown strength in solid dielectrics. As was shown quite early, an area effect exists since larger area electrodes include more defects or weak points. Larger electrode areas result in lower breakdown strength, as was shown in experiments with Teflon films [6]. Larger electrodes also produce shorter average breakdown times [6]. Authors in [7], worked with spherical and cylindrical electrodes at power frequency and indicated that a pronounced area effect exists since much lower breakdown strength results were obtained with cylindrical depressions [7]. Early breakdown studies were somehow related with the notion of "intrinsic electric strength", a notion prevalent at that time [8]. Later research indicated that this notion was erroneous and that the so-called intrinsic breakdown strength was not a property characterizing the insulating solids [9]. As is written in [9], "this word "intrinsic" reflecting history in that early theories stimulated belief in the existence of a physical constant, independent of geometry, electrode material, voltage waveform, and determined by molecular and/or crystal structure and temperature. The concept, is not supported by experiment". Admittedly, one cannot find much data on the electrode area effect on the breakdown strength of solid dielectrics. However, the general lines that are followed in the other categories of insulating materials, are also followed in the case of solid dielectrics, namely that the breakdown strength depends on the configuration of the electrodes, that the physical shape of the electrodes gives the variation of the breakdown voltages, and that the above mentioned quantities define the electric field distribution [10].

\section{CRYSTALLINITY}

Earlier experiments with various types of organic insulating materials indicated that the breakdown strength of polyethylene was not affected by doubling its crystallinity [11]. Polystyrene, however, a partially aromatic polymer, showed a considerable reduction in the breakdown strength by increasing the ordered structure of the polymer $(4.9 \mathrm{MV} / \mathrm{cm}$ was the average breakdown strength for isotactic polystyrene pressed film compared to $7.1 \mathrm{MV} / \mathrm{cm}$ for atactic polystyrene pressed film). The isotactic character of the polystyrene gives a crystallisable polymer, which permits a favorable geometry for interaction between the adjacent benzene rings [11]. Other researchers, investigating the dielectric properties of thermally aged biaxially orientated polypropylene (BOPP), observed that surface degradation was much faster than the bulk degradation although the total thickness of the films was no more than $25 \mu \mathrm{m}$. They also showed that the morphological nature of BOPP films changed during thermal aging. The crystallinity of BOPP increased by thermal aging since recrystallization of part of the amorphous phase occurred. The interfacial domain of crystalline and amorphous phases may play a significant role for various properties of semi-crystalline polymers including breakdown strength [12]. During aging, changes in the chemical structure of polymers may alter processes such as softening or melting above their glass transition temperature and consequently, changes in their chemical structure may 
occur. Less obvious physical effects, such as secondary crystallization in partially crystalline materials may occur and may cause increased stiffness and structural relaxation in an amorphous component rendering thus densification and embrittlement possible [13].

An important point is made in [14], where it is remarked that "a polymer melt has structural viscosity, i.e the macromolecules are orientated according to the shear velocity. [Since] non-Newtonian polymer melt displays a velocity distribution that is more uniform in the central section of the flow [and] the velocity gradient close to the boundary surface is higher ... salient orientations and stretchings of the macromolecules occur in these zones ...[consequently] orientations [that] are initially retained in the insulation and are frozen during the cooling process by reduction of the chain mobility and crystallization" may cause inhomogeneities with a subsequent effect on breakdown strength. On the other hand, swelling of a polymer - in case of impregnation with liquid may be reduced by some factors such as crystallinity. Authors in [15] reported that the breakdown strength of both polythene and polypropylene depends mainly on their semi-crystalline structure and the presence of defects rather than their chemical structure, since the two polymeric materials have similar values of breakdown strength. The preponderant role of defects was also emphasized in $[16,17]$, since defects can vary from those of molecular dimensions up to gross defects arising from inclusions. In a more recent publication, performing tests on polyethylene terephthalate (PET) with AC voltage, it was remarked that the breakdown strength is reciprocal to the longest free path [18]. Although the authors of [18] did not specifically study the relation between material crystallinity and breakdown strength, they tacitly imply the relation between the two aforementioned quantities. Furthermore, they noted that in thicker films, the boundaries between amorphous and crystalline parts can be a cause of inhomogeneities, thus reducing breakdown strength. More recently, authors in [19] investigated both ceramic ( $\mathrm{A} 12 \mathrm{O} 3, \mathrm{TiO} 2, \mathrm{SrTiO} 3$, and $\mathrm{BaTiO} 3)$ and polymeric materials (PMMA, polystyrene and n-butyl acetate) and used the so-called dielectric breakdown toughness (Gbd) which is related to the critical energy release necessary to initiate the unstable growth of the longest conducting filament in the sample surface [19]. Evidently, such a quantity is related also to the very structure of a polymer.

Since a polymer consists of amorphous and crystalline regions, some sort of cause that will modify the relation between these two regions, will necessarily have an influence on the breakdown strength. The microhardness $(\mathrm{MH})$ of a polymeric material can be expressed as

$$
\mathrm{MH}_{\mathrm{c}}=\alpha \mathrm{H}+(1-\alpha) \mathrm{H}_{\mathrm{a}}
$$

where $H_{c}$ and $H_{a}$ are the hardness values of the crystalline and amorphous regions respectively and $\alpha$ is the volume fraction of the crystalline region [20]. Authors in [20] showed that the microhardness of a polymer decreases with temperature, with the decrease following an exponential law of the type:

$$
\mathrm{H}=\mathrm{H}_{0} \cdot \mathrm{e}^{-\beta \mathrm{T}}
$$

where $\mathrm{H}_{0}$ is a constant, $\mathrm{T}$ is the temperature $\left({ }^{\circ} \mathrm{C}\right)$, and $\beta$ is the coefficient of thermal softening. According to [20], a decrease in microhardness is mainly associated to the softening of the crystalline region. An increase in the thickness of amorphous region - and therefore a decrease in crystallinity - will result to a decrease of the breakdown strength of the insulating material $[21,22]$. On the other hand, working with poly (ether ether ketone) - PEEK, which is a high temperature insulating thermoplastic, it was observed that the breakdown strength decreased by increasing the crystalline/amorphous ratio of the polymer $[23,24]$. The author attributed this to the fact that increased crystallinity introduces breakdown pathways not present in the amorphous material.

Investigating BOPP samples, researchers relatively recently remarked that the breakdown strength increased substantially when the initially spherulitic morphology was transformed into a highly ordered fibrillar network structure of densely packed lamellar crystallites aligned parallel to the film surface [25]. In accordance with the above, it was reported by other researchers that with DC high voltage, the breakdown strength increases with increasing crystallinity because the free volume of polyethylene becomes smaller as the crystallinity increases [26]. Thus the free path of electrons decreases and it is more difficult for them to accelerate. Consequently, there is an increase in breakdown strength. It is evident from the above that the effect of crystallinity on the breakdown strength of polymers depends on the very chemical structure of the materials as well as on the defects that may be included.

\section{IMPREGNATION EFFECT}

Impregnation of solid insulation with appropriate liquids is necessary in order to avoid the risk of partial discharges and/or early breakdown. The impregnating liquids must have a suitable viscosity, so that they can impregnate micro-cavities that may exist in the solid insulation [1]. It has been established that an impregnated system prepared without sufficient care against contamination and/or possible micro-cavities may be subject to several mechanisms, which may cause its ultimate deterioration [16]. Quite early it was shown that the nature of the impregnating liquid is most important for the electrical behavior of a composite insulating system. The breakdown strength of low density polyethylene (LDPE) extruded film was reported to be lower when the film was immersed into oDichlobenzene than when it was immersed into transformer oil or chlorinated biphenyls. Many pre-breakdown discharges were evident in the o-Dichlorobenzene in contrast to either the transformer oil or the chlorinated biphenyls [11]. Silicone oil or diethyleneglycol were shown to impregnate XLPE cable insulation better since they both indicated considerable improvement in breakdown strength. Such liquids exhibited a $50 \%$ or even better increase in impulse and AC breakdown strength. This improvement was attributed to the moderation of the fatigue mechanism when liquid replaced gas in the microspaces and consequently to a reduction in the energy of ionic or electronic deteriorative process [27]. In further studies, other researchers continued working on XLPE cables considering filling the microporosities in XLPE with appropriate gases (such as SF6). They showed that the AC breakdown strength as well as the partial discharge behavior improved [28]. In [15], DC and impulse breakdown strength of polypropylene increased by impregnation with suitable dipolar 
liquids (hexachlorodiphenyl -HCP, trichlorodiphenyl - TCP, dibutyl phthalate-DP) at both room and liquid-air temperatures. The breakdown strength of polythene impregnated with chlorinated diphenyl was also found to increase at room temperature under impulse conditions.

High stability is required from the combination of polymeric insulation and the impregnant since they have to resistant to thermal degradation and to oxidation $[29,30]$. Low viscosity oils are preferable because of their better impregnation when in contact with polymers. Moreover, low viscosity oils absorb gas more easily than heavily viscous oils [31]. As was pointed out more recently, "the gas absorption property of an impregnating liquid together with its viscosity determines to a very great extent the partial discharge performance of the liquid impregnated system" [32]. A low viscosity and high gas absorption capacity oil is always desirable in order to have low discharge activity and consequently a high breakdown strength. A combination of polymer and of a low viscosity absorbing liquid was proposed several years ago. That was a combination of uniaxially orientated polyethylene (UOPE) and dodecylbenzene (DDB) oil [33-35]. Experimental results indicated that since collision impact of electrons accelerated in the free volume is the dominant cause for electrical tree initiation, liquid impregnation is a promising way to improve the performance of polymeric materials and to rise the breakdown strength [36]. Swelling of the polymer is another parameter determining the behavior of a composite insulation and must be avoided since the breakdown strength of the composite insulation can be seriously deteriorated. Previous work on this has shown that the AC breakdown strength of a polypropylene laminated paper/oil combination decreases as swelling worsens [37]. Similar conclusions were reached with another composite insulating system consisting of UOPE/DDB oil [33-35]. In [38], the problem of solid/liquid combination was attacked from another angle, namely that of the interface and also in terms of the water content. It was concluded that the breakdown voltage is reduced more dramatically when temperature is low and water content is also low. Swelling of polypropylene (PP) films with rapeseed oil was not that significant and, moreover, the oil impregnation rose the breakdown strength from $640 \mathrm{~V} / \mu \mathrm{m}$ to $810 \mathrm{~V} / \mu \mathrm{m}$. This rise was attributed to the diffusion of the rapeseed oil into the PP film. With oil diffusion, the PP foil structure becomes more regular as the free volume of the dielectric is filled with the impregnant. Therefore the electric field distribution in the case of applied voltage becomes more homogeneous and thus the breakdown strength of the PP foils increases [39]. The advantages of rapeseed oil (good impregnation, good resistance to aging) were also reported in [40]. It must be noted, however, that rapeseed oil lacks w.r.t. aging vegetable oil which has excellent resistance to aging [41].

\section{TEMPERATURE EFFECT}

Temperature has long been recognized of having a significant effect on the breakdown process of solid insulating materials. Quite early it was reported, among other types of deterioration, the thermal depolymerization of polymeric insulating materials. At elevated temperatures, polymer chains break into smaller units and this can happen even when oxygen is not present [42]. More recently, some other researchers, investigating oil filled kraft-paper cable at high temperature for a long time, reported that there will eventually be a failure because of saturation of the impregnant by gas formed as a result of thermal degradation of the cellulose [43]. Experiments with polyethylene films indicated that the breakdown strength decreases with increasing temperature. As an explanation, it was put forward the electron thermal runaway in localized electron system caused by the interaction with conduction electrons [21].

Other researchers looked at the temperature effect from another interesting viewpoint, namely that of the temperature influence during sample preparation. In this case, temperature may greatly influence the morphology of a polymer and also the field necessary for tree initiation. As ambient temperature increases, both tree initiation and breakdown occur at lower stresses [44]. Experiments with low-density polyethylene (LDPE) samples of various thicknesses showed that in the range of $80^{\circ}$ to $100^{\circ} \mathrm{C}$, breakdown strength increased. Above and below this temperature range, the slope of temperature dependence of breakdown strength was observed to be negative. Such a behavior could be explained by suggesting that the input energy rate from impulse voltage is partly devoted to melt the crystalline lamellae increasing thus the amorphous parts and decreasing the electron mobility. Consequently, an increase of the electric stress is needed to trigger a breakdown [45].

Orientated polymers seem to be more stable than nonorientated polymers. However, as mentioned in [29], orientated polymers may be subjected to a rapid shrinkage above a critical temperature. Degradation of UOPE films has been observed several years ago, especially when these are combined with DDB oil [33-35]. Besides the fact that such a composite system (UOPE/DDB oil) starts having problems at about $110^{\circ} \mathrm{C}$, oils with aromatic constituents can cause crazing to polymers much more easily than polybutene oil $[46,47]$. On the other hand, polybutene oil has poorer gas absorbing characteristics, its absorption rate of hydrogen being equal to $1 / 9$ of that of the DDB oil [48]. Regarding composite solid/liquid insulating systems, it is worth noting that, in earlier decades some researchers investigating the gassing characteristics of mineral oils, reported that an increase in temperature leads to an increase in gas absorption as well as in gas evolution $[49,50]$. Elevated temperature tests turn out to give lower breakdown strength, which may be due to an increase of the thickness of the amorphous region of the polymer and to the greater solubility and diffusivity of the gaseous byproducts. Greater solubility and diffusivity in turn will sustain discharges of a certain magnitude and will possibly cause discharges of an even larger magnitude, which will erode the polymer with accelerating rate and will eventually lead to failure [33-35].

Measurements with DC voltages showed that the breakdown strength of fluorinated parylene (PA-F) decreased with increasing temperature from ambient up to $350^{\circ} \mathrm{C}$. The authors attributed the decrease to the fact that the thermal energy induces changes leading to the acceleration of free electrons. Moreover, as the temperature increases, the trapped 
electrons are freed more easily with less electric field needed. A further contributing factor to the decrease of the breakdown strength is the decrease of the material density due to the free volume increase [51]. Such an interpretation is in agreement with previous publications $[52,53]$. The interpretations of [5153] are not fundamentally different from the interpretations given earlier [45]. The free volume increase, the accumulation of internal heat and of the space charges cause an increasing electric field distortion with increasing temperature and thus they become the contributing factors for the decrease of breakdown strength of XLPE with DC voltages [54]. In [55], polyethylene terephthalate (PET) showed a decrease of breakdown strength going up from $33^{\circ} \mathrm{C}$ to $73^{\circ} \mathrm{C}$ because of as the authors claimed - the activation of thermal breakdown pathways [55]. Such an approach is not radically different from the interpretation given in [21].

The work performed with thin and thick dielectric films introduced yet another parameter. It was observed that while the breakdown strength decreased with increasing temperature, such a decrease was less noticed with thicker samples than with thinner samples. It was suggested that the breakdown strength is less sensitive to temperature for thicker samples because the electromechanical mechanism is the dominant mechanism for the dielectric breakdown $[56,57]$. On the other hand, their interpretation for the dependence of the thinner samples was similar to the interpretation put forward in [51].

\section{THE ROLE OF INTERFACES}

Interfaces play a significant role in determining the breakdown strength of solid dielectrics. Differing phases may also play a role. The interfacial domain between crystalline and amorphous phases may well determine the various properties of semi-crystalline polymeric materials [58]. Interfacial breakdown was studied with a variety of electrode systems. Paper and transformer oil were used as insulation. When the paper was not carefully dried, interfacial breakdown would occur [59]. In [59], however, was also noted that with a carefully prepared paper-oil interface, breakdown did not necessarily took place at the interface. Such observations were also made later with silicone rubber interfaces [60]. Modern insulating systems, such as those with solid dielectrics, did not avoid problems of interfaces, since there were interfaces of semi-conducting sheaths with the main insulation or the inclusion of microcavities and/or impurities [61, 62]. The role of microcavities at interfaces between solid and solid dielectric was treated in [63]. Microcavities between solid dielectrics, especially with the applied field parallel to the interface, enhance the risk of low breakdown strength. Such risk may be avoided if a mechanical pressure is applied to the two solids. Mechanical pressure (i.e. contact pressure) implies a better contact between the two surfaces and consequently, a better interface [64, 65]. In [66], the same research group claimed that lubricated interfaces offer higher breakdown strength than nonlubricated interfaces. Moreover, in silicone rubber-silicone rubber interfaces, despite the fact that air voids are the limiting factor, the injection of liquids/gels to air voids is of vital importance for high breakdown strength. Authors in [64-66] confirmed the observations and conclusions of earlier works $[67,68]$. In a further work, one of the authors of [66] distinguished between vented and enclosed cavities at an interface between solid-solid dielectrics, and he proposed the idea that discharges inside such cavities may develop to streamers, which in turn will lead to breakdown. The gas pressure inside the enclosed cavities is likely to increase as a function of the change in the size of the cavity, the extent of which is dependent on the contact pressure and elastic modulus. Increased gas pressure, in turn increases the discharge field strength of the cavities according to Paschen's law [69].

The threshold electric field for partial discharge initiation depends primarily on the solid dielectric under stress, when the surrounding medium is air or liquid. This threshold field was shown to be much lower in the case of solid-air interfaces than in the case of solid-liquid interfaces. Such experimental data indicated the importance of impregnation with liquids [70]. Quite early research pointed out that prolonged heating in a composite solid-liquid insulating system affects mainly the solid component, and in the case of paper-oil system, a significant increase of acidity was observed. Evidently, the increase of acidity of the oil after prolonged heating in the presence of paper was due to the degradation of the paper and not to the alteration of the oil [71]. Furthering and extending the thoughts of [71], it was shown later that - with polycarbonate impregnated with low viscosity mineral oil ionizable impurities in mineral oil enhance space charge losses. The latter in turn causes the lowering of breakdown strength [72]. The importance of ionic carriers for the dielectric behavior of a polypropylene/oil system was also noticed in [73]. Considering the role of interfaces on lapped taped polymers (such as HDPE, polypropylene, and nylon impregnated with supercritical helium) authors in [74] indicated that there is no tendency for the discharges and breakdown to concentrate in butt gaps adjacent to the metal conductor. The butt gaps next to the conductor were no more frequently the seat of breakdown than the butt gaps in the interior of the insulation. In this respect, the authors in [74] reached similar conclusions with the authors in [59, 60]. More recently, the importance of the difference between the permittivities of the solid dielectric and the liquid insulant was emphasized w.r.t the electric field applied parallel to the interface. As the solid dielectric has - as usually is the case - a higher permittivity than the liquid, the initial streamer will convert to breakdown as the strong attractive force causes the streamer to settle on the interface. Parallel high permittivity liquid immersed dielectrics accelerate the charge transport between the electrodes [75]. The conclusions of [75] are in accordance with those published earlier, where it was remarked that the flashover mechanism is initiated in the liquid immediately adjacent to the spacer/liquid interface as a consequence of electric-field intensification induced by permittivity mismatching between the solid and the liquid [76].

As noted elsewhere, breakdown strength depends on the quality of the interfaces. Due attention must be paid to the choosing of the materials for specific applications and to the construction of the composite insulating system. Interfaces in the conventional insulating systems, can be considered as the weak aspects of such systems. Without the need of an exaggeration, one can conclude that the problems arising in 
high voltage applications are for the most part problems of interfaces [77].

\section{MECHANICAL STRESSING}

In the context of the present paper we will not deal with mechanical stressing and its effect on electrical trees in solid dielectrics (since this topic has been dealt before [78]) nor we will deal with internal residual mechanical stresses. The aim here is to somehow mention several studies in relation to the mechanical stressing to the breakdown strength of soli dielectrics. About four decades ago, it was shown that both DC and impulse breakdown strength of polythene increased by compression. The effect of changing from an uncompressed to a compressed sample was an increase of $38 \%$ in the mean breakdown strength (from 0.61 to $0.84 \mathrm{GV} / \mathrm{m}$ ) [15]. Indications of the influence of mechanical stressing on the breakdown strength of polythene were given even earlier, when it was noted that its impulse strength at $80^{\circ} \mathrm{C}$ was much higher than the breakdown strength of the same material tested under the same temperature with a slowly applied electric stress [79]. The beneficial effect of compressive stresses can be understood on the basis of an initial increase of density, which results in closing up voids and to increase molecular packing. On the other hand, the compressive stresses may cause the breakage of tie-bonds and create defects. This is the reason for which, experiments with PET and epoxy resin showed that, although initially there was an increase of breakdown strength, subsequently it decreased. Tensile stresses may cause crack initiation and growth. Such stresses may cause defects at the amorphous-lamellae interfaces of semi-crystalline polymers (such as polyethylene and polypropylene) [80]. The observations of [80] confirmed previous research, where it was indicated that elongation causes a decrease of breakdown strength for both LDPE and HDPE, no matter what sort of voltage was applied (AC, DC, and impulse). The authors attributed the decrease to defects produced by mechanical stretching [81]. Confirmation of [80], as to the perplexing effect of compressive stresses on polymers, was reported recently [82], where the authors investigated the breakdown strength of an acrylic dielectric elastomer. The authors especially emphasized on the relation between the electrode configuration and the applied compressive stresses. Tensile stresses may have a beneficial effect with some polymeric materials since they tend to decrease thickness and consequently to increase breakdown strength. Such data were given with transparent silicone polymers in [83].

A recent report tackled the problems of both tensile and compressive stresses. It stated that when the silicone rubber is subjected to a tensile stress, the molecular chains are stretched in the stress direction leading to fracturing. On the contrary, when a compressive stress is applied, the molecular chains come closer and they generate more attraction bonds and consequently more stabilization in the silicone rubber structure [84]. In yet another recent publication, it was reported that the accumulated damage is higher in the case of tensile stress than in the case of compressive stress, whereas the space charge, free volume and partial discharges increase in the presence of tensile stresses and decrease in the presence of compressive stresses [85].

\section{SOME GENERAL REMARKS}

In this paper, a brief review on some factors affecting the breakdown strength of polymeric materials is given. Although effects such the area effect are more or less clear by now, other factors, such as the role of crystallinity, need further clarification. As was noted recently, the effect of polymer crystallinity on breakdown strength is a problem of carrier mobility in general. As carrier mobility increases, breakdown strength decreases. Therefore polymers with higher crystallinity have lower breakdown strength than those with lower crystallinity. On the other hand, if polymers have a lot of small crystallites (even if crystallinity is large), inter-crystal boundaries may reduce mobility, and therefore increase breakdown strength. Detailed states of polymers (morphology, impurities, crystal-amorphous boundary conditions, density of boundaries, length of crystals and amorphous regions) play a crucial role [86]. Carrier mobility also increases as temperature increases in both crystalline and amorphous regions and drastic increase in mobility is anticipated especially in the amorphous regions [86]. The influence of mechanical stresses is also a subject in need of further exploration since with tensile stresses there is a critical value for crack formation, whereas with compressive stresses there is the possibility of breakage of tiebonds and of creation of defects.

\section{CONCLUSIONS}

The present paper deals with some factors affecting the breakdown strength of polymeric materials. Factors such as the area of the electrodes, the polymer crystallinity, the impregnation of polymers, the temperature effect, the quality of interfaces, and the effect of mechanical stresses are investigated and commented upon. In the context of this brief review, only conventional polymers were considered.

\section{REFERENCES}

[1] D. Kind, H. Karner, High-voltage insulation technology, Springer, 1985

[2] M. S. Naidu, V. Kamaraju, High voltage engineering, McGraw-Hill, 1995

[3] C. L. Wadhawa, High voltage engineering, New Age Science, 2001

[4] W. R. Bell, "Influence of specimen size on the dielectric strength of transformer oil", IEEE Transactions on Electrical Insulation, Vol. 12, No. 4, pp. 281-292, 1977

[5] M. G. Danikas, "Breakdown of transformer oil", IEEE Electrical Insulation Magazine, Vol. 6, No. 5, pp. 27-34, 1990

[6] T. W. Dakin, H. M. Philofsky, W. C. Divens, "Effect of electric discharges on the breakdown of solid insulation", Transactions of the American Institute of Electrical Engineers, Part I: Communication and Electronics, Vol. 73, No. 2, pp. 155-162, 1954

[7] D. H. Shroff, A. W. Stannett, "Contribution to the study of electric strength of polythene", Proceedings of the Institution of Electrical Engineers, Vol. 114, No. 6, pp. 832-833, IEEE, 1967

[8] H. Frohlich, "Dielectric breakdown in solids", Reports on Progress in Physics, Vol. 6, No. 1, pp. 411-430, 1939

[9] R. Cooper, "Breakdown in solids", in: Electrical Insulation, Peter Peregrinus Ltd., pp. 33-51, 1983

[10] K. L. Ratnakar, B. R. Kamath, "Influence of electrode configuration on AC breakdown voltages", International Journal of Research and Scientific Innovation, Vol. 4, No. 6, pp. 60-63, 2017

[11] J. J. McKeown, "Intrinsic electric strengths of organic polymeric materials", Proceedings of the Institution of Electrical Engineers, Vol. 112, No. 4, pp. 824-828, IEEE, 1965 
[12] T. Umemura, D. Couderc, "Thermal aging of biaxially oriented polypropylene films. Part II: Morphology and dielectric properties", Conference on Electrical Insulation \& Dielectric Phenomena-Annual Report, Amherst, USA, October 17-21, 1982

[13] G. C. Stevens, "Thermal evaluation and life testing of solid insulation", in: Electrical Insulation, Peter Peregrinus Ltd., pp. 197-218, 1983

[14] T. Tanaka, A. Greenwood, Advanced power cable technology: Volume II-present and future, CRC Press, 1983

[15] J. J. Fendley, N. Parkman, "Effect of impregnation, compression and temperature on electric strength of polythene and polypropylene", IEE Proceedings A (Physical Science, Measurement and Instrumentation, Management and Education, Reviews), Vol. 129, No. 2, pp. 113-118, 1982

[16] N. Parkman, "Breakdown in composites", in: Electrical Insulation, Peter Peregrinus Ltd., pp. 52-69, 1983

[17] M. Kahle, Elektrische isoliertechnik, Springer, 1988

[18] K. Theodosiou, I. Vitellas, I. Giallas, D. P. Agoris, "Polymer films degradation and breakdown in high voltage AC fields", Journal of Electrical Engineering, Vol. 55, No. 9-10, pp. 225-231, 2004

[19] C. Neusel, G. A. Schneider, "Size-dependence of the dielectric breakdown strength from nan-to millimeter scale", Journal of the Mechanics and Physics of Solids, Vol. 63, pp. 201-213, 2014

[20] J. M. Salazar, J. G. Pena, B. Calleja, "On the relation between hardness and intermolecular forces in polyethylene crystals", Polymer Communications, Vol. 26, No. 2, pp. 57-59, 1985

[21] Y. Inuishi, "High field conduction and breakdown in solid dielectrics", IEEE Transactions on Electrical Insulation, Vol. 15, No. 3, pp. 139-151, 1980

[22] T. Fukuda, S. Irie, Y. Asada, M. Maeda, H. Nakagawa, N. Yamada, "The effect of morphology on the impulse voltage breakdown in XLPE cable insulation", IEEE Transactions on Electrical Insulation, Vol. 17, No. 5, pp. 386-391, 1982

[23] T. W. Giants, "Crystallinity and dielectric properties of PEEK, a thermoplastic poly(ether ether ketone)", Space and Missile Systems Center, Air Force Material Command, Los Angeles Air Force Base, 1993

[24] T. W. Giants, "Crystallinity and dielectric properties of PEEK, poly(ether ether ketone)", IEEE Transactions on Dielectrics and Electrical Insulation, Vol. 1, No. 6, pp. 991-999, 1994

[25] I. Rytoluoto, A. Gitsas, S. Pasanen, K. Lahti, "Effect of film structure and morphology on the dielectric breakdown characteristics of cast and biaxially oriented polypropylene films", European Polymer Journal, Vol. 95, pp. 606-624, 2017

[26] D. Li, L. Zhou, X. Wang, L. He, X. Yang, "Effect of crystallinity of polyethylene with different densities on breakdown strength and conductance property", Materials, Vol. 12, No. 11, Article ID 1746, 2019

[27] A. L. McKean, "Breakdown mechanism studies in cross-linked polyethylene cable", IEEE Transactions on Power Apparatus and Systems, Vol. 95, No. 1, pp. 253-260, 1976

[28] A. L. McKean, K. Tsuji, H. C. Doepken, A. Zidon, "Breakdown mechanism Studies in cross-linked polyethylene cable: Part II", IEEE Transactions on Power Apparatus and Systems, Vol. 97, No. 4, pp. 1167-1176, 1978

[29] J. Staight, "properties and applications of solid/liquid composites", in: Electrical Insulation, Peter Peregrinus Ltd., pp. 146-163, 1983

[30] A. W. Stannett, "Breakdown testing and measurements on installed equipment”, in: Electrical Insulation, Peter Peregrinus Ltd., pp. 261-276, 1983

[31] F. M. Clark, "Dielectric strength of mineral oils", Transactions of the American Institute of Electrical Engineers, Vol. 54, No. 1, pp. 50-55, 1935

[32] K. P. Mammootty, T. S. Ramu, "Properties of castor oil impregnated allpolypropylene and polypropylene-paper capacitors", IEEE Transactions on Electrical Insulation, Vol. 18, No. 5, pp. 541-550, 1983
[33] M. G. Danikas, A study of the behaviour of a uniaxially orientated polyethylene tape/oil insulating system subjected to electrical and thermal stresses, University of London, 1985

[34] A. J. Pearmain, M. G. Danikas, "A study of the behavior of a uniaxially oriented polyethymene tape/oil insulating system subjected to electrical and thermal stresses", IEEE Transactions on Electrical Insulation, Vol. 22, No. 4, pp. 373-382, 1987

[35] M. G. Danikas, "Study of samples of a composite insulating system under electrical and thermal stresses", IEEE Electrical Insulation Magazine, Vol. 6, No. 1, pp. 18-23, 1990

[36] N. Shimizu, H. Tanaka, "Effect of liquid impregnation on electrical tree initiation in XLPE", IEEE Transactions on Dielectrics and Electrical Insulation, Vol. 8, No. 2, pp. 239-243, 2001

[37] T. Tanaka, "Characteristics of composite insulation: Liquid-impregnated insulation", IEEE Transactions on Electrical Insulation, Vol. 21, No. 6, pp. 881-888, 1986

[38] M. Hasheminezhad, E. Ildstad, A. Nysveen, "Electrical breakdown strength of interfaces between solid insulation and transformer oil with variable water content", Annual Report Conference on Electrical Insulation and Dielectric Phenomena, Quebec, Canada, October 26-29, 2008

[39] A. Aschneuwly, P. Groening, L. Schlapbach, P. Bruesch, M. W. Carlen, R. Gallay, "Temperature-dependent dielectric breakdown strength of oil impregnated polypropylene foils", Materials Science and Engineering: B, Vol. 54, No. 3, pp. 182-188, 1998

[40] D. K. Mahanta, S. Laskar, "Electrical insulating liquid: A review", Journal of Advanced Dielectrics, Vol. 7, No. 4, Article ID 1730001, 2017

[41] I. L. Hosier, A. Guushaa, E. W. Westenbrink, C. Rogers, A. S.Vaughan, S. G. Swingler, "Aging of biodegradable oils andassessment of their suitability for high voltage applications", IEEE Transactions on Dielectrics and Electrical Insulation, Vol. 18, No. 3, pp. 728-738, 2011

[42] T. W. Dakin, "Electrical insulation deterioration treated as a chemical rate phenomenon", Transactions of the American Institute of Electrical Engineers, Vol. 67, No. 1, pp. 113-122, 1948

[43] G. Head, P. S. Gale, W. G. Lawson, "Effects of high temperatures and electric stress on the degradation of oil-filled cable insulation", $3^{\text {rd }}$ International Conference on Dielectric Materials, Measurements and Applications, Birmingham, UK, September 10-13, 1979

[44] J. H. Mason, "Assessing the resistance of polymers to electrical treeing", IEE Proceedings A (Physical Science, Measurement and Instrumentation, Management and Education, Reviews), Vol. 128, No. 3, pp. 193-201, 1981

[45] K. Yahagi, A. Okinaka, S. Katakai, "High temperature breakdown characteristics in polyethylene film with fixed electrodes", IEEE Transactions on Electrical Insulation, Vol. 18, No. 2, pp. 138-142, 1983

[46] J. C. Devins, C. W. Reed, "Crazing of glassy polymers in oilimpregnated cables", Conference on Electrical Insulation \& Dielectric Phenomena-Annual Report, Pocono Manor, USA, October 12-14, 1971

[47] E. O. Forster, Private communication with M. G. Danikas, 1983

[48] A. C. M. Wilson, Insulating liquids: Their uses, manufacture, and properties, Institution of Engineering and Technology, 1980

[49] A. A. Zaky, I. Y. Megahed, "Effect of organic additives, gas phase, stress, and temperature on the gassing characteristics of insulating liquids", IEEE Transactions on Electrical Insulation, Vol. 7, No. 3, pp. $145-152,1972$

[50] U. Pelagatti, "A new synthetic impregnant for high tension hollow core cables", Annual Report Conference on Electrical Insulation, White Sulphur Springs, USA, November 3-6, 1963

[51] R. Khazaka, M. Bechara, S. Diaham, M. L. Locatelli, "Parameters affecting the DC breakdown strength of parylene F thin films", Annual Report Conference on Electrical Insulation and Dielectric Phenomena, Cancun, Mexico, October 16-19, 2011

[52] H. Zhou, F. G. Shi, B. Zhao, "Thickness dependent dielectric strength of PECVD low-k carbon doped silicon dioxide dielectric thin films: Modeling and experiments", Microelectronics Journal, Vol. 34, No. 4, pp. $259-264,2003$ 
[53] H. Zhou, F. G. Shi, B. Zhao, J. Yota, “Temperature accelerated dielectric breakdown of PECVD low-k carbon doped silicon dioxide dielectric thin films", Applied Physics A, Vol. 81, pp. 767-771, 2005

[54] K. Qian, P. Su, J. Wu, Y. Yin, "Effect of thickness on breakdown strength in high voltage direct current cable insulation at different temperatures", Proceedings of the CSEE, Vol. 38, No. 24, pp. 71217130, 2018

[55] C. B. Belcher, L. Appelhans, "Effect of temperature and metallization thickness on the dielectric properties of polyethylene terephthalate", Proposed for presentation at the AVS Symposium, Albuquerque, New Mexico, May 24, 2016

[56] H. K. Kim, F. G. Shi, "Thickness dependent dielectric strength of a lowpermittivity dielectric film", IEEE Transactions on Dielectrics and Electrical Insulation, Vol. 8, No. 2, pp. 248-252, 2001

[57] H. K. Kim, S. W. Lee, F. G. Shi, B. Zhao, "Thickness dependent temperature accelerated dielectric break-down strength on on-wafer low dielectric constant polymer films", KIEE International Transactions on Electrophysics and Applications, Vol. 2C, No. 6, pp. 281-286, 2002

[58] T. Umemura, K. Akiyama, T. Kashiwazaki, "Dielectric behavior of solid/liquid insulation system", IEEE Transactions on Electrical Insulation, Vol. 17, No. 3, pp. 276-280, 1982

[59] E. F. Kelley, R. E. Hebner, "Electrical breakdown in composite insulating systems: Liquid-solid interface parallel to the field", IEEE Transactions on Electrical Insulation, Vol. 16, No. 4, pp. 297-303, 1981

[60] M. G. Danikas, "On the breakdown strength of silicone rubber", IEEE Transactions on Dielectrics and Electrical Insulation, Vol. 1, No. 6, pp. 1196-1200, 1994

[61] A. Ernst, A. Muller, The state of development of $100 \%$ synthetic tape at Brookhaven National Laboratory, Internal Report, BNL-28981, Brookhaven National Laboratory, USA, January 1981

[62] B. Yoda, K. Muraki, "Development of EHV cross-linked polyethylene insulated power cables", IEEE Transactions on Power, Apparatus and Systems, Vol. 92, No. 2, pp. 506-513, 1973

[63] F. H. Kreuger, Industrial high voltage: Electric fields, dielectrics, constructions, Delft University Press, 1991

[64] S. M. Hasheminezhad, E. Ildstad, A. Nysveen, "Breakdown strength of solid/solid interface", 10th IEEE International Conference on Solid Dielectrics, Potsdam, Germany, July 4-9, 2010

[65] S. M. Hasheminezhad, "Breakdown strength of solid/solid interfaces", IEEE Trondheim PowerTech, Trondheim, Norway, June 19-23, 2011

[66] E. Kantar, D. Panagiotopoulos, E. Ildstad, "Factors influencing the tangential AC breakdown strength of solid-solid interfaces", IEEE Transactions on Dielectrics and Electrical Insulation, Vol. 23, No. 3, pp. 1778-1788, 2016

[67] H. G. Benken, "Ueber die elektrische festigkeit von fugen zwischen festen isorierstoffen", Schweizerische Technische Zeitschrift, Vol. 65, No. 23, pp. 501-503, 1968 (in German)

[68] H. G. Benken, Ueber die elektrische festigkeit von fugen zwischen festen Isorierstoffen, $\mathrm{PhD}$ Thesis, Technische Universitaet Braunschweig, 1967 (in German)

[69] E. Kantar, Longitudinal AC electrical breakdown strength of polymer interfaces: Experimental and theoretical examination of solid-solid interfaces considering elasticity, surface roughness, and contact pressure, $\mathrm{PhD}$ Thesis, Norwegian University of Science and Technology, 2019

[70] A. X. Moronis, P. D. Bourkas, "Impact ionization effects at interfaces between solid dielectrics and insulating oil or air, during high voltage pulse applications", Interface Science, Vol. 2, pp. 281-287, 1995

[71] P. G. Priaroggia, G. L. Palandri, U. A. Pelagatti, "The influence of ageing on the characteristics of oil-filled cable dielectric", Proceedings of the IEE-Part A: Power Engineering, Vol. 108, No. 42, pp. 467-479, IEEE, 1961

[72] R. Bartnikas, "Dielectric losses in solid-liquid insulating systems: Part II”, IEEE Transactions on Electrical Insulation, Vol. 6, No. 1, pp. 14-21, 1971

[73] T. Umemura, K. Akiyama, T. Kashiwazaki, "Dielectric behavior of a solid/liquid insulation system", IEEE Transactions on Electrical Insulation, Vol. 17, No. 3, pp. 276-280, 1982
[74] B. M. Weedy, S. Shaikh, S. G. Swingler, "Partial discharges in lapped polymer taped insulation impregnated with supercritical helium", IEE Proceedings A (Physical Science, Measurement and Instrumentation, Management and Education, Reviews), Vol. 129, No. 3, pp. 176-181, 1982

[75] J. Jadidian, Charge transport and breakdown physics in liquid/solid insulation systems, $\mathrm{PhD}$ Thesis, Massachusetts Institute of Technology, 2013

[76] R. J. Taylor, "Effect of permittivity matching on the flashover of solid/liquid interfaces", Proceedings of the Institution of Electrical Engineers, Vol. 124, No. 10, pp. 899-904, 1977

[77] M. G. Danikas, R. Sarathi, "Interfaces in high voltage engineering: A most important question for conventional solid insulating materials as well as for nanocomposite polymers", FunkTechnikplus\#Journal, Vol. 1, No. 4, pp. 7-31, 2014

[78] M. G. Danikas, D. Papadopoulos, S. Morsalin, "Propagation of electrical trees under the influence of mechanical stresses: A short review", Engineering, Technology \& Applied Science Research, Vol. 9, No. 1, pp. $3750-3756,2019$

[79] R. A. Fava, "Intrinsic electric strength and electromechanical breakdown in polythene", Proceedings of the Institution of Electrical Engineers, Vol. 112, No. 4, pp. 819-823, 1965

[80] L. A. Dissado, J. C. Fothergill, Electrical degradation and breakdown in polymers, Peter Peregrinus, 1992

[81] S. Mita, K. Yahagi, "Effect of elongation on dielectric breakdown strength in polyethylene", Japanese Journal of Applied Physics, Vol. 14, No. 2, pp. 197-201, 1975

[82] B. Chen, M. Kollosche, M. Stewart, J. Busfield, F. Carpi, "Electrical breakdown of an acrylic dielectric elastomer: Effects of hemispherical probing electrode's size and force", International Journal of Smart and Nano Materials, Vol.6, No. 4, pp. 290-303, 2015

[83] C. Lothongkam, "Dielectric stresngth behavior and mechanical properties of transparent insulation materials suitable to optical monitoring of partial discharges", $\mathrm{PhD}$ Thesis, Universitaet Hannover, 2014

[84] B. X. Du, J. G. Su, J. Li, T. Han, "Effects of mechanical stress on treeing growth characteristics in HTV silicone rubber", IEEE Transactions on Dielectrics and Electrical Insulation, Vol. 24, No. 3, pp. 1547-1556, 2017

[85] R. S. A. Afia, E. Mustafa, Z. A. Tamus, "Mechanical stresses on polymer insulating materials", International Conference on Diagnostics in Electrical Engineering, Pilsen, Czech Republic, September 4-7, 2018

[86] T. Tanaka, Private communication with M. G. Danikas, 2020 